\title{
Impact of Organisational Structure on Employee Engagement: Evidence from North Central Nigeria
}

\author{
Adeoye K. Funminiyi
}

Department of Management, University of Nigeria, Nsukka, Nigeria.

\begin{abstract}
In the current workplace, organizational structure assumes priority in the level of employee engagement. Therefore, well planned structure results in workers efficiency and organizations effectiveness. This study assessed the impact of organizational structure on employee engagement in North Central of Nigeria. Adopting a survey design, the research made used of primary data, collected mainly through administering a set of questionnaire to 196 management staff, supervisors and non-management staff of the selected manufacturing firms from Plateau state. The findings revealed that: there is significant positive relationship between decentralisation system of control and employee productivity; standardisation system of control positively affects employees' efficiency. The study concluded that decentralisation system of control is crucial to employees' productivity and organisational development; also enhance rapid delivery of employee services, to both the organization and customers. Standardisation system of control ensures employee efficiency and generates quality products that give competitive edge over the competitors in the global market Incentives as key factor also contribute immensely to employee commitment in workplace. The work recommended that organisations should always employ decentralization system of control; management should adopt decentralization and see it as mechanism that fosters effective customer delivery services. In addition standardisation should be embrace, support and adopt by organizations.
\end{abstract}

Keywords - Decentralisation, Efficiency, Job security, Organisational structure, Productivity, Performance and Standardisation.

\section{INTRODUCTION}

In the global business environment, best practices are expected of organisations in order to compete favourably and consider key players in the international market. Organisations that want to play along in the globalize market may have to structure their organisational design towards decentralisation and standardisation system of control that will focus on operational excellence, global competition, innovation and synergy among skilful employees. However, management goals should be unanimous with the interest and expectation of their employees respectively.

Organisational structure is a crucial integral part of organisation. The nature of structure can be an impediment or development to such organisation. Actually, firms that aimed to survive and improve in global market are expected to exhibit a well design structure that will improve employees' engagement and unanimously attain organisational goals. The efforts of employees are keys to the accomplishment of organis ational overall objectives.

Preliminary studies revealed that centralise system of control is common in manufacturing firms in Nigeria, which result in low level of employee job involvement and low productivity. In the real sense, it was observed that interpersonal relationship is lacking between supervisor and subordinate, which on the contrary generate job dissatisfaction among employees. As structure play important roles in improving employee's engagement if being in place.

Consequently, these myriad of problems if left unchecked could constitute negative impact on employee's efficiency and perhaps organisation productivity. Organizations that fail to integrate decentralise and standardise systems of control, well equipped, skilled and committed employees are bound not to stand the test of time in the global market to compete.

Also, in an organisation where the level of motivation is low or non-existing, employees tend to experience job dissatisfaction that will automatically lead to low performance.

In addition, evidence has shown that organisations that discourage effective organisational structure, employee's involvement and participation in decision making, teamwork and collaborative effort among workers will experience decline in performance. Thus, this study focuses on impact of structure on employee engagement in selected Manufacturing Firms in North Central, Nigeria.

It is against this background that the study seeks to examine the impact of organisational structure on employee engagement in manufacturing firms Nigeria. It is believed that the findings will generate strategic ideas 
that will enhance employees' efficiency and quality products in their respective responsibilities. However, the study aimed to establish the following objectives:

i. To ascertain how decentralisation system of control affects employee productivity.

ii. To assess the extent of the relationship between standardisation system of control and employee's efficiency.

The following researcher questions are raised

i. How does decentralisation system of control affect employee's productivity?

ii. What is the nature of relationship between standardisation system of control and employee's efficiency?

\section{REVIEW OF LITERATURE AND THEORETICAL FRAMEWORK}

The Concept of Organizational Structure

An organizational structure is the functional framework, aligning resources with defined organizational objectives in the business strategy and embodying the organization's culture. The structure directly impacts the company's capability to attract, engage and retain employees.

An organizational structure is a logical framework of the department. It lays out and defines priorities through design of positions with generalist and specialist roles, indicates reporting relationships and the fit of each person in the big picture, and establishes decision making as centralized or decentralized. Effective implementation of organization structure entails clarity of task responsibilities to enable employees to work well together and jointly manage overlapping duties and hand-offs with each other (Erickson, 2005).

An effective organizational structure has its roots in making a positive impact on the employee and business and, therefore, is aligned with the business strategy. It flows with the company culture. And, it is designed to attract and accommodate high performing individuals, through creation of positions that leverage their highest skills and provide development and growth, ensuring meaningful work and a sense of purpose from the present into the future.

Organisation strives to be the best competitor in the environment they are competing and among the players in the same industry (Macey \& Schnieder ,2008). Mean while, the structure implored or adopted can have an influence on employee's engagement, therefore they should examine this fact, and productivity must be high for any organisation to achieve the competitive advantage. But if low can take the organisation down the drain.

The organisational structure indicate is the way of doing business, how each change is implemented and how each job description is made, how the communication of the organisation will work and the strategic plan to enhance employee engagement (Perrin, 2003)

If one then take the elements of an organisational structure and examine them to see if it can make a difference in how tasks are executed and managed. These elements are decentralisation, centralisation and levels of management, and these elements are the main foundation of any organisational structure. But how can the structure have an influence on the attitude and engagement of employees? Peter Christensen has identified the main objective in the study of employee's relationship with organisational structure. He said that Maslow's theory of needs identifies the security and safety needs, and is safe to say that all employees who had security and safety in their working environment will have a positive reaction towards the management and organisational structure if coordinated appropriately. How do we give employees security and safety in a working environment, one work on the attitude and engagement of each employee (Ellis \& Sorensen, 2007). By examining this problem and illuminate it from working conditions one can have a structure that helps employees to exhibit positive reaction, work faster and more productive. Organisational structure is the coordination of a specific organisation's individuals and team work. If an organisation coordinates the individual's task they can achieve all goals and specific objectives. Organisational structure is one of few mechanisms an organisation can use to coordinate and manage all subordinates, because of the way it shows the different reporting relationships, cut out the "middleman" in the communication structure and identifies the worker's actions and how they come together. All organisations can use structures, though some differ from others but all structures have some advantages and disadvantages. Even though an organisation has the best structure it is not something the organisation should leave and not manage, some of the best structures have failed because of inadequate management and it is not the best suitable structure for the environment the organisation does business (Carpenter, Bauer \& Erdogan 2009).

Employee Performance

Employee performance is a set of standards set out for each employee's behaviour in his or her workplace environment. The specific criteria not only focuses on how the employee makes use of his time, by doing his work, but can be compared by some standards set out by the employer (Moore 2011).

\section{Productivity}

Productivity can be defined as the overall output of goods or services produced divided by the inputs needed to generate that output. (Robbins \& Coulter 2003). Some factors which can have an impact on productivity is: employee attitude, the owner (boss), health, working 
environment, working equipment, outsourcing and downsizing.

\section{Traditional Structure and New Modern Structure}

Critical assessment of organisations structure will enable one to understand the management style been adopted by a specific organization. These management styles indicate how the organisation is run and if employees perform better or worse. The two main styles are:

A hierarchical management structures (traditional structure).

A flatter and more open "humanistic" management structures (New modern structure).

The traditional organis ational structure

Traditional organisational structure's most common fact is that it shows distinct demarcation or boundary between the management level and the lower levels (subordinates). The only reason for this boundary is to show that management is first on the hierarchy and that all decisions have to be made by them. Whereas employees are seen as bottom dwellers and they are insignificants in their workplace environment, this however gives the management more stress and has an impact on the training and motivation for the rest of the employees. Therefore, this is responsible for reaction on employee job engagement and how they respond towards management actions.

The traditional structure has two levels:

Level one: Managers, these include top management, middle management and lower management.

Level two: Employees

This type of structure is outdated and very ancient and research shows that humans have used it from the start of humanity. However the structure is common it has some advantages and is most used if a team has to collaborate together to find lasting solutions for problems. The management style is used in armed forces and is also known as the military management style.

The modern organis ational structure

The structure is more flat and open; employees and management can be seen as equal persons aiming for mutual goals and objectives. There is no clear boundary between managers and employees, as in the case of traditional management style. This gives employees the right to use their creativity and receives rewards for the work they have done. Rewards = Employees satisfaction $=$ Employee actively engage $=$ Improved productivity.

Modern structures are synonymous with individuals and teams who can manage themselves, employees become multi skilled, training investments increase, few status distinctions, more objectives are accomplish, employee security is guarantee, outsourcing becomes more acces sible and stable structure.

Types of Modern Organizational Structures

$$
\text { 1. Functional Organisational Structure }
$$

2. Geographic Organisational Structure

3. Product Organisational Structure

4. Market or Users Organisational Structure

5. Hybrid Organisational Structure

6. Matrix Organisational Structure

(Konrad, 2006).

Problems associated with organizational structures are; organisational structures can never show all of the links involved in the organisation, communicating with other employees on different levels, department conflict. The time it takes on developing products takes longer. Customer demands become too high for certain levels (Liebowitz, 2008).

The Factors Influencing the Choice of Structure Adopted

1. The magnitude of the organisation: The size of an institution some time determines the type of organization structure to integrate into the system.

2. Employees competency and skilfulness: A Matrix structure will be preferred if the company has a high level of creative and innovative workers.

3. The leadership style: If owners wish to maintain control they will use a narrow (centralize) structure and others who wants employees to participate in decisions making will use a wider (decentralize) structure.

4. Organizational goals and objectives: Organization that aims at growing faster will incorporate a wide structure.

5. External influence: If country is experiencing recession the organisation will need to reduce the working force and change the structure from wide to narrow or make it more flat.

6. Technological changes: The development of administrative systems disables the layer of administration and the organization will retrench some of the employees in the particular or specific category.

Organisations choose of structure is extremely pertinent to employee engagement therefore, they should be careful; the wrong structure can have huge negative impacts on the communication, costs, decisions making and in motivating employees. This has the same effect on the employee's attitudes towards the structure and will end up in employee low level of engagement and corresponding lower productivity.

\section{Centralisation}

Centralisation is a process in which the decision making is assigned and devoted to the different higher levels of the structure. Centralisation keeps off employees from vital knowledge and information that are related to the organization, when an organisation uses top management 
in making decisions they take away the innovative of employees and only tell employees what to do. What happens to employees when they aren't motivated and self-manageable, they can't solve problems on their own, especially when useful information cannot reach employee on time. Centralisation has a broad span of control in top levels and more tiers in the structure of the organisation.

\section{Decentralization}

Decentralization is a process where lower levels management or employees of the organisation has privileges to participate in decision making. Many decisions are made at lower levels, this gives employees the motivation to be creative and be innovative, and solve the problems in their own sectors (Carpenter et al, 2009). Decentralization is the movement of decision making to some of the other sections of the organization; these units can be the branches, divisions and subcontractors. If given all employees the right to make decisions, it will improve workers, in the aspect of creativity, knowledge and ideas to engage in their respective tasks. Employees are given more authority and can improve their attitudes towards responsibilities, if they fell wanted in the organisation. The structure's span of control is smaller and more levels are given.

The three forms of decentralization

1. Deconcentration: this is the lowest level of decentralisation and decisions are made at the lower levels of the organisation by technician.

2. Delegation: Is a more modern system of decentralisation, the decisions are made by lower levels and correspondingly, they have more authority in the organisation.

3. Devolution: This type of decentralisation only engages autonomous organisational units when making decisions

\section{Standardisation}

This refer to the uniform and consistent that employees are to follow in doing their jobs, such as written procedure, job descriptions, instructions, rules and regulations are employed to standardize the routine aspects of tasks. Standard permit managers to measure employees' performance against established criteria. Job descriptions and application forms standardize the selection of workers. If assignments were not follow a specific standard, many organizations will not ascertained their respective goals.

\section{Matrix Structure}

Matrix structure is an organizational chart that encourages active participation of employees in decision making. This enables them to use their skill for different task in their assigned duties. The fundamental advantage of matrix structure is that it allows the members of the team to share relevant information more freely across boundaries which would otherwise have existed. Also, individuals can be chosen to suit the requirements of a project and the team will be more dynamic and creative that they will be able to approach certain problems in different ways. There will be a named business or project manager who is responsible for completing assigned task, so workers will know whom they are responsible to, and the project supervisor will be aware of the specific deadlines and budget constraints of the business.

Disadvantages of matrix management structure styles include conflicts over the allocation of resources between line managers and project managers. If a team has too much autonomy then the projects may be more difficult to manage than if they were more closely monitored. High cost of implementing projects if more managers are required to manage project teams. Individuals may also need to acquire new skills and quickly address certain issues including coordinating others and managing themselves.

The matrix management structure is now largely viewed as the preferred approach and the general feeling is that the structure embrace and support more effective use of resources, including the human resource, as well as making the company a more comfortable and conducive place to work. Teams may only exist for the period of the project and then be moved on to work in another different teams depending upon the skills the individuals can demonstrate.

\section{The Concept of Employee Engagement}

According to Gallup organization employee engagement is the involvement with and enthusiasm for specific task. (Dernovsek, 2008) posit that employee engagement is positive employees' emotional attachment and employees' commitment. (Robinson, Perryman \& Hayday, 2004) stated that employee engagement is a positive attitude held by the employee towards the organization and its value. An engaged employee is aware of business context, and works with colleagues to improve effectiveness within the job for the benefit of the firms. The organization must work to improve and sustain engagement, which requires a two-way relationship between employer and employee.

This verdict and definition forwarded by Institute of Employment Studies gives a clear insight that employee engagement is the result of two-way relationship between employer and employee pointing out that there are responsibilities to be executed by both parties. Furthermore, (Fernandez, 2007) shows the distinction between job satisfaction, the well-known construct in management, and engagement contending that employee satisfaction is not the same as employee engagement and since managers cannot rely on workers satisfaction to help retain the best and the brightest, employee engagement becomes a critical concept. Other researchers take job 
satisfaction as a part of engagement, but it can merely reflect a superficial, transactional relationship that is only as good as the organization's last round of perks and bonuses; Engagement is about passion and commitment; the willingness to invest oneself and expand one's discretionary effort to assist the employer succeed, which is beyond simple satisfaction with the employment arrangement or basic loyalty to the employer Blessing White, (2008). Therefore, the full engagement equation is established by aligning maximum job satisfaction and maximum job contribution. (Steven. Elias, Rakesh \& Mittal, 2011) the executive director of Towers Perrin, also distinguishes between job satisfaction and engagement contending that only engagement (not satisfaction) is the strongest predictor of organizational performance.

The negative aspect for management is that global surveys conducted by survey houses and research organizations indicate that significant size of employees are disengaged being sceptical of any organizational initiative or communication and rather more likely indulging in contagious negativity (Dernovsek, 2008).

\section{The need for Employee Engagement}

Employee engagement is the extent to which employee commitment; both emotional and intellectual exist relative to accomplish the work, mission and vision of the organization (Schmidt, Henges, \& Bryson, 2003). Employee engagement is a part of employee retention. It integrates the classic constructs of job satisfaction (Schmidt et al., 2003) and organizational commitment (Meyer \& Allen, 1991). Engaged employees take into cognisance the future of the company and are willing to invest discretionary effort (Seijts, Gerard \& Crim, 2006). Engaged employees feel a strong emotional bond to the organization that employs them, which creates higher retention level; improve productivity levels and lower absenteeism. When reliably measured, positive employee engagement can be casually related or correlated to specific business outcomes by team and job type (Robinson, Dilys \& Hayday, 2003). An engaged worker is one who is fully involved in, and enthusiastic about their responsibilities, and thus will act in a way that furthers their organization's interest. Engagement can be seen as a heightened level of ownership where each employee wants to do whatever they can for the benefit of their external and internal customers, and for the success of the organization as a whole (Lockwood, 2007).

According to (Spreitzer, 1995), engagement has four dimension: meaning (sense of purpose), competence (selfefficacy), feelings of self-determination (feelings of control) and impact (belief that one's efforts can make a difference).There is clear confirmation that high level of employee engagement keenly correlates to individual, group or corporate performance in areas such retention, turnover, productivity, customer service and loyally. Some of the distinct advantages of engaged employees included better performance and more motivation; higher organizational profitability; and higher staff retention rate. Additionally, higher engaged employees are associated with the company and its products and services, and contribute to bottom line business success. Competitive engagement environment creates a sense of loyalty, provides a high energy working environment and engaged employees serve as a brand ambassador of the organization. These advantages emanate from the fact that there will be emotional attachment and retention. Employees who are actively engaged in their jobs work with passion and feel a profound connection to their institutions.

They help promote the organization and they believe they can positively impact quality of their organization's products (White, 2010). Engages subordinates feel a strong emotional bond to the organization that employs them and demonstrate a willingness to recommend the organization to others and commit time and effort to help the organization succeed (Konrad, 2006). Furthermore, employee engagement has the potential to create involvement and commitment by workers. This highinvolvement will produce superior performance. In addition, workers in the high involvement organization show more positive attitudes including trust organizational commitment and intrinsic enjoyment of their work (Konrad, 2006).

Employee engagement levels have a direct impact on employee productivity and consequently on the company's bottom line. Engaged employees use their talent and strengths effectively at work every day to deliver high levels of performance consistently. At the same time, employees who are not engaged, not only erode the bottom line with their lack of productivity, they also foster negativity at every opportunity, thus impacting team performance (Konrad, 2006). It has been routinely found that employee engagement scores account for as much as half of the variance in customer satisfaction. Studies have statistically demonstrated that engaged employees are more productive, more profitable, more customer focused, safer and less likely to leave their employer. Employees with the highest level of commitment perform $20 \%$ better and are $87 \%$ less likely to leave the organization which indicates that engagement is linked to organizational productivity (Lockwood, 2007).

\section{Drivers of Employee Engagement}

They are:

1. Align efforts with strategy

2. Empowerment 
3. Promote and encourage teamwork and collaboration effort

4. Training and workshop for growth and development

5. Leadership support and recognition where appropriate

\section{Employee Engagement Strategies}

1. Acquisition and Retention Strategies: Most organizations do have clear new talent acquisition strategies. Meanwhile, they lack employee retention strategies. Effective recruitment and orientation programs are the fundamental foundations to be laid on the first day of the new worker. Managers should be careful in pooling out the potential talent of the new employee through effective recruitment. The newly hired employee should be given general orientation which is related to the company mission, vision, values, policies and procedures and job-specific orientation such as his or her job duties, and responsibilities, goals and current priorities of the division to which the employee belongs, in order to enable him or her to develop realistic job expectations and reduce role conflict that might arise. After the hiring decision is made, the manager has to ensure role-talent fit when placing a subordinate in a certain position and exert all managerial efforts needed to retain that talent in the organization.

2. Leadership Support; Employee engagement requires manager support through establishing specific mission, vision and values. Unless the people at the top believe in it, own it, make it available to subordinates and employees, and enhance their leadership, employee engagement will never be more than just a "corporate fad" or "another HR thing". Employee engagement does not need lip-service rather dedicated heart and actionoriented service from top management. It requires "Leading by Being Engage or Practice"

3. Manager-Employee Inputs; Managers should promote two-way communication. Employees are not sets of pots to which you pour out your ideas without allow them to contribute on issues that matter to their task and life. Clear and consistent communication of what is expected of them paves the way for engaged workforce. Engage your workers and always show respect to their input. Share power with your employees through participative decision making so that they would feel sense of belongingness thereby enhancing their engagement in work.

4. Development and advancement: Encourage independent thinking through giving them more job autonomy so that employees will have a chance to make their own freedom of choosing their own best methodology of executing problems, so long as they are producing the expected result. Manage through results rather than trying to manage all the processes by which that result is achieved.

5. Resources Availability: Managers are expected to make sure that employees have all the resources such as physical or material, financial and information resources in order to effectively engage with their job.

6. Employees Training: Update and equip employee current knowledge and skills through giving appropriate trainings. Generally it is understood that when employees get to know more about their job, their confidence increases there by being able to work without much control or supervision from their immediate managers which in turn builds their self-efficacy and commitment.

7. Effective Feedback Mechanism: Companies should develop and maintain a performance management system which holds managers and workers accountable for the level of their engagement at workplace. Conducting regular assessment of employee engagement level helps make out factors that make employees engaged.

After finalizing the evaluation, it is advisable to determine all the factors that driving engagement in the organizations, then narrow down the list of factors to focus on two or three areas. It is important that organizations begin with a concentration on the factors that will make the most difference to the employees and put energy around improving these areas as it may be difficult to address all factors at once. Managers should be behind such survey outcomes and develop action-oriented plans that are specific, measurable, and accountable and time- bound.

8. Incentives: Managers should fashion out and introduce both financial and non-financial benefits for employees who show serious engagement in their tasks respectively. Several management theories have revealed that when employees get more pay, recognition and praise, they tend to exert more effort into their job.

There should be a clear link between productivity and incentives given to the employees.

9. Distinctive corporate culture: Companies should promote a strong work culture in which the goals and values of managers are aligned across all work sections. Companies that build a culture of mutual respect by keeping success stories alive will not only keep their existing employees engaged but also they baptize the new incoming workers with this contagious spirit of work culture.

10. Top-performing employees: A study conducted by Watson Wyatt Worldwide in 2004 to 2005 on Human Resource practices of 50 large USA firms shows that high-performing organizations are focusing on engaging their top-performing employees. According to the finding of the same research, the high-performing firm are meeting the expectation of their employees therefore, 
reduces the turnover of high-performing employees and as a result leads to top business performance.

\section{Productivity Relating to Organizational Structure}

Organisational structure designed and how the top management level provide sufficient motivation and support for employees can break the business or can turn it positive to become successful. The design of the structure should follow crucial procedures that will ensure it effectiveness, if it isn't, the organisation stand the risk of demotivating employees and having a negative influence on their attitude, which in return influence the productivity of the organisation and all employee, and in the end they may loose some employees in the future because of ineffective management and lack of a perfect structure (Math 2010).

\section{Factors Influencing Productivity}

1. Confidence: Organisational structures that are consistent give employees security and a positive behaviour towards their task. A consistent structure is one where the hiring of employees are within the organisation, workers are promoted when they are performing and when employees can relax about job loss. If an organisation has a constant and reliable structure, employees will devote their effort and perform best in workplace, which gives an organisation a higher production rate (Math 2010).

2. Shared Goals: Transparent structures can have an impact on how employees strive towards the objectives of the division or unit, when an organisation can set their own goals align with employee expectations, they will be able to motivate the team into a better productive mode and accomplished higher standards. Organisations can, for example; if they are busy with a new budget and plans for the next financial year, they can share it with middle management and ask them to do so with their own divisions and sectors. This will enable the employees to understand organisational goals, when these specific objectives are set each employee can set his or her goals which they want to achieve for the next year. Organisations can also notify employees when goals are actualize, so that these employees can evaluate how their progress are going to make sure all set goals are met and achieved (Math 2010).

3. Accountability: All organisations should put in place a strong modality of reporting system, when this system is not in place, employees will not know what to do with problems or generated ideas. The idea of these types of systems is to make sure that no information is useless, when employees have challenges they should be able to talk to someone to reduce or eradicate it, if an employee has a better way of doing his job, he should be embraced and the innovative idea be explored. However if this structure is not effective, this information can get lost, demotivate employees and give them negative attitudes towards management which will have an influence on the culture, productivity and success of the organisation (Math 2010).

$\begin{aligned} & \text { Organizational Structures and Employees } \\ & \text { Engagement } \\ & \text { 1. Organizational Structure and Employee } \\ & \text { Performance }\end{aligned}$

The key determinant of organizations effectiveness is the performance of their workers. Therefore, employee need to adequately engage in the responsibilities assigned to them, so as to ascertain organizational goals. This is the vision of most companies to be able to compete favourably in the globalize market.

The basic idea of an organisational structure is to enhance decision making and to identify how the organisation system is working and who has the authority to make the relevant decisions and what team works in which units and programs. Employee's interest is to be recognized in an organization or in their sections. When employees are recognized they are motivated. This gives them the positive attitude towards the organisation and the management of the organisation, when employees attitudes change from negative to positive, it create a platform for employee to be fully engage, which is what organisations want; higher performance from employees. Now if the structure is made from the idea of the old traditional type of body, employees can't get the motivation and positive attitude, which in turn deterred their engagement and consequently gives lower performance ratio towards the organisation. This type of structure is not the only one that can have a negative influence on subordinate, even modern structures can, if not utilized in the correct manner or if the structure is not align with the type of organisation. (Meijaard, Brand \& Mosselman. 2002).

1. Organizational Chart and Job Security

Maslow's hierarchical model indicated that person's security needs are high. If organisational structure improves employee security, the result will be an employee with a positive attitude and subordinate who will work towards achieving greatness and overall company objectives.

2. Flexible Management Structures and Employee Efficiency

Management is one of the most essential factors of an organisation, how they do their work and how they relate 
with employees. Though within traditional structures one cannot have these types of flexible management structures, but it is visible under modern structure. A flexible management structure gives the employees the motivation to be a part of a team and an idea. Employees that are given the opportunity to make a contribution towards a working program and give ideas are creative and innovative in the sense that they feel wanted by the organisation and they will be more efficient..

\section{Decentralize Organizational Structure} and Employee Productivity

In the present volatile business environment, organizations employed and retain employees who can think for themselves. When an employee can manage themselves the managers will not need to coordinate or give instruction to subordinates on how to carry out specific task will have less conflict and be proactive, the bottom line is that active workers will want to exercise or engage their skill and experience. Now, if all employees are self-managed, management may not need to do check and balancing and can do their own work effectively, this will increase the working capacity, proper employee engagement, which will lead to higher productivity.

\section{Theoretical Framework}

1. Motivation Theory

Baron (1986) distinguished between two opposing philosophies of human nature towards work as proposed by McGregor. Theory $\mathrm{X}$ which takes a pessimistic view of human motivation to task and Theory $\mathrm{Y}$ which is more optimistic and assumes workers are not passive and are ready to assume responsibilities and develop skills according to their organization's needs. The accuracy of Theory Y assumptions depends on the extent to which management creates policies and motivational mechanisms that enable employees develop their own potential. Today's organizational culture has generally shown that workers have moved away from the tradition of viewing work as a form of punishment and now place a high value on work for its own good. The motivation to work has become a cherished value in society. This is especially so among managerial and professional workers who report that having a challenging job is more important than the amount of earnings. Clerical and unskilled employees also place high value on their work environment both social and physical than on the pay itself. This theory revealed that organizational structure determines employee engagement in an organization.

2. Path Goal Theory

The path-goal theory, also known as the path-goal theory of leader effectiveness or the path-goal model, is a leadership theory developed by Robert House (1996). The theory states that a leader's behaviour is contingent to the satisfaction, motivation and performance of her or his employees. The revised version also argues that the leader engages in behaviours that complement subordinate's abilities and compensate for inefficiencies. The path-goal model can be classified as a transaction leadership theory. According to the first of all theory, the manager's job is viewed as guiding workers to choose the best channels to reach their goals, as well as the organizational goals. The theory argues that leaders will have to engage in different types of leadership behaviour depending on the nature and the demands of a particular situation. It is the leader's responsibilities to assist followers in attaining goals and to provide the direction and support needed to ensure that their goals are compatible with the organisation's goals (Crook, Todd, Combs, Woehr, \& Ketchen, 2011).

Path-goal theory assumes that leaders are flexible and that they can change their style, as situations require. The theory proposes two contingency variables, such as environment and follower characteristics, that moderate the leader behaviour-outcome relationship. Environment is outside the control of the follower-task structure, authority system, and work group. This theory support the variable on leadership styles (Crook et al, 2011). This theory of leadership was tested against the variable on democratic leadership style and its effect on labour relations and organisational performance. The theory indicate how effective structure in organization influence employees engagement.

\section{Affective Events Theory}

Affective events theory (AET) is a model developed by organisational psychologists Howard M. Weiss (Purdue University) and Russell Cropanzano (University of Colorado) to illustrate how emotions and moods influence job performance and job satisfaction. The model explains the linkages between employees' internal influences (e.g., cognitions, emotions, mental states) and their reactions to incidents that occur in their workplace environment that affect their engagement, performance, organisational commitment, and job satisfaction. The theory proposes that affective work behaviours are explained by employee mood and emotions, while cognitive-based behaviours are the best predictors of job satisfaction. The theory proposes that positive-inducing (e.g., uplifts) as well as negative-inducing (e.g., hassles) emotional incidents at work are distinguishable and have a significant psychological impact upon workers' job satisfaction. This results in lasting internal (e.g., cognition, emotions, mental states) and external affective reactions exhibited through workers engagement, job performance, job satisfaction, and organisational commitment. The Affective Events Theory explains the link between employees' internal influences and their reactions to incidents that occur in their workplace environment that affect their engagement, performance, organisational commitment and job satisfaction (Phua, 2012). It 
proposes that positive-inducing as well as negative emotional incidents at work have significant psychological impact on employees' job satisfaction. The impact results into lasting reactions exhibited through employee's engagement, job satisfaction, organisational commitment and job performance. This theory confirms the fact that organizational structure affects employee engagement.

\section{METHODOLOGY}

The research adopts survey method and design. The geographical area of this research is Jos, Plateau states, Nigeria. The state was selected because it have well functional manufacturing firms in the North Central region, Nigeria. The population of the research consists of the staff of selected three manufacturing firms which were selected purposively. The populations of this staff were 397. The researcher determined the size of the sample, a total of 196 samples were derived from the study population with the use of Trek formula (Trek, 1994). Data for the work were collected mainly from primary source through questionnaire that were self-administered. The answer options for the questionnaire were developed using five-point Likert scale with SA - Strongly Agree, A - Agree, U - Uncertain, D - Disagree and SD - Strongly Disagree.

Table.1: The population studies are the staff of the three key selected manufacturing sectors. The populations of this staff are:

\begin{tabular}{|c|l|l|l|}
\hline $\begin{array}{l}\text { N } \\
\text { o }\end{array}$ & \multicolumn{1}{|l|}{ Manufacturing firms } & $\begin{array}{l}\text { Popula } \\
\text { tion }\end{array}$ & $\begin{array}{l}\text { Samp } \\
\text { le }\end{array}$ \\
\hline 1. & $\begin{array}{l}\text { Nasco Food Nig. Ltd., 44 } \\
\text { Yakubu Gowan Way, Jos. } \\
\text { Plateau State }\end{array}$ & 60 \\
\hline 2. & $\begin{array}{l}\text { Diamon Paints Nig. Ltd. Jos. } \\
\text { Plateau State. }\end{array}$ & 134 & 67 \\
\hline 3. & $\begin{array}{l}\text { Vital Foam Plc. Jos Plateau } \\
\text { State. }\end{array}$ & 70 \\
\hline & Total & $\mathbf{3 9 7}$ & $\mathbf{1 9 6}$ \\
\hline
\end{tabular}

SOURCE: Managers, Human Resources Departments of the selected firms, (2018)

\section{ANALYSIS, RESULTS \& DISCUSSION}

Out of the one hundred and ninety-six (196) questionnaires administered, only one hundred and ninety-seven (175) representing 89.29\% were returned and found good for the data analysis.

The biographical information of the respondents from the analysis revealed that many of the respondents of the selected three manufacturing firms were male (78.1\%). Also, majority of the respondents in the organizations were of middle and low level managerial positions $(89.5 \%)$ which definitely give the work more meaningful responses since the issues relating to employees commitment affect these management cadres most. Furthermore, most of the respondents (77.1\%) were unskilled employees. This is a pointer that the findings would give reliable results since the works majorly emanate from the concern for the unskilled workers. Finally, our respondents come mostly from marketing (35.8\%) and operation (31.9\%) departments. These give us a true representation to justify the significant roles of leadership styles on employee's productivity.

\section{Testing of Hypotheses}

Two hypotheses were formulated and are tested as follow using ANOVA and chi-square. Hypothesis one was tested with One-way ANOVA and hypothesis two was tested with chi-square test. SPSS was used to analyze the various tests.

\section{Hypothesis one:}

HO: there is no significant relationship between decentralisation system of control and employee productivity

HA: there is significant positive relationship between decentralisation system of control and employee productivity.

Table.2: One-Way ANOVA

Customer Satisfaction and Sales revenue

\begin{tabular}{|l|l|l|l|l|l|}
\hline & Sum of Squares & Df & Mean Square & F & Sig. \\
\hline Between Groups & 2795.300 & 4 & 1341.281 & .687 & .002 \\
Within Groups & 3219.300 & 13 & 162.421 & & \\
Total & 3985.400 & 15 & & & \\
\hline
\end{tabular}

Source: SPSS analysis of field data 2017

Hypothesis two:

HO: standardisation system of control has no effect on employees' efficiency.

HA: standardisation system of control positively affects employees' efficiency. 
Table.3: Chi-Square Test Statistics.

\begin{tabular}{|l|l|l|}
\hline & Workers and collaborative efforts & Organizational productivity \\
\hline Chi-Square & 24.61 & $5.29 \mathrm{~b}$ \\
Df & 198 & 6 \\
Asymp. Sig. & 5.29 & 1.000 \\
\hline
\end{tabular}

The chi-square is computed at 0.05 level of significant

Source: SPSS analysis of field data 2017

The relationship between decentralisation system of control and employee productivity

Data for the test of this hypothesis were obtained from responses through questionnaire. The one-way ANOVA was used to test the extent of the relationship between decentralisation system of control and employee productivity. Tables 2 reveals that while the f-distribution result shows the existence of relationship result on the variables $(F=0.687$ at $p<0.05)$. The significant level is 0.002 , and due to this we reject the null hypothesis and accept the alternate one which states that there is significant positive relationship between decentralisation system of control and employee productivity.

The effect of standardisation system of control on employee's efficiency

Having analyzed the second hypothesis on table 3 with chi-square (x2), we found out that the calculated figure is greater than the tabulated figure $(x 2 \mathrm{Calc}=24.61>$ $x 2 \mathrm{Tab}=5.29$ ), we reject the null hypothesis and accept the alternate which signifies that standardisation system of control positively affects employees' efficiency.

\section{CONCLUSION AND RECOMMENDATIONS}

This work identifies the determinant of employee engagement of manufacturing sectors by reviewing works on organisational structure and by finding how the independent variables affect the dependent variables. Although previous studies shows multifaceted results workers' productivity in the aspect of decentralisation leadership style of control, this work revealed that decentralisation system of control is crucial to employees' productivity and organis ational development.

Decentralisation leadership style is the act of control that managers take into cognisance, contribution and relevant suggestions from employee to facilitate operational processes, decision-making and accomplishment of strategic objectives. Employee participation in decisionmaking make them to feel recognise and ready to assume responsibility of the outcome of the assigned task. This established the fact that the variable is a determinant that is of special significance to employee's engagement.

Besides, decentralisation system of control create avenue for rapid change as the business environment is volatile and subsequently complex. Units will not need to wait for centre command before taking decision that will positively affects the organisation. This will enhance rapid delivery of employee services, to both the organization and customers. Standardisation system of control ensures employee efficiency and generates quality products that give competitive edge over the competitors in the global market. Correspondingly, employees will acquire adequate skill and technical know-how that will be an instrumental to efficiency and quality products.

In line with the actual study findings and conclusions drawn, the following recommendations were suggested:

1. Organisations should always employ decentralization system of control. This will encourage decision to be made closer to operational level of work, in return address the persistent issues of delay in decision making which result in non-committed on the part of employees and low productivity.

2. Decentralization is an approach that requires managers who and when to delegate, to select and develop personnel and to formulate appropriate control. This recommendation improves and sustains high level of responsiveness to local circumstances. Consequently, it increases employee degree of engagement to their jobs. Hence, business organizations operate in diplomatic and volatile environments. Besides, internally generated problems can be promptly and probably addressed.

3. In addition, it enhances level of customer service. Therefore, management should adopt decentralization and see it as mechanism that fosters effective customer delivery services, considering the geographical or regional location of the business organization.

4. Standardisation is pertinent to employee efficiency. In the sense that workers will exert their discretionary effort to ascertained best outputs. In the light of this, it must be meticulously and systematically integrated, harness and sustains by organizations to ascertain their specific objectives and compete favourably in the international market. 
5. Standardisation is the uniform and consistent procedures that employee are to follow in execute their tasks. It entail equipping and empowering employee for quality products, which in return will result to economic development and growth. Really, standardisation should be embrace, support and adopt by organizations.

\section{REFERENCES}

[1] Baron, R.A. (1986). Behaviour in organizations. New York: Allyn \& Bacon, Inc.

[2] Blessing White. (2008). The Employee Engagement Equation in India. Presented by BlessingWhite and HR Anexi. [Online] Available: www.blessingwhite.com (May 21, 2018.

[3] Carpenter, R.T.,Buier, E., \& Erdogen, A.. (2009). Employee Engagement and Talent Management. [Online] Available: www.watsonwyatt.com (May 21, 2018).

[4] Crook, E., Todd, N., Comms, G., Wreter, A. and Katchan, H. (2011), Training determinants and productivity impact of training in China: A case of Shanghai. Economics of Education Review, 24(8), 275.

[5] Dernovsek D. (2008). Creating highly engaged and committed employee starts at the top and ends at the bottom line Credit Union Magazine, May 2008. Credit Union National Association, Inc.

[6] Ellis, E.. M., \& Sorenisen, A. F. (2007) Career development and employee commitment in industrial organisations in Calabar, Nigeria: American Journal of Scientific and Industrial Research.1(2).

[7] Eriksson, T. S. (2005). The Adoption of Job Rotation: Testing the Theories. Industrial and Labor Relations Review, 653-666.

[8] Fernandez. C.P. (2007). Employee engagement. Journal of Public Health Management and Practice. [Online] Available: http://find.galegroup.com. (May 21, 2018).

[9] Konrad, H. A. (2006) The impact of human resource management practices on turnover, productivity, and corporate financial performance. Academy of Management Journal, 38 (1), 635-672

[10] Liebowitz, D. (2008). "Impact of workplace quality on employee's productivity: A case study of a bank in Turkey." Journal of Business, Economics \& Finance 1(1): 38-49.

[11] Lockwood, B. (2007). Kenya's competiveness in the floriculture industry: A test of porters competitive advantage organizations and the boundary less career. Journal of Vocational Behaviour, 2(8), 112-129.

[12] Math, B. (2010). Middle level manpower development, skill acquisition and utilization in industries. Journal of Organizational Behaviour, $8(2), 47-53$.

[13] Macey W.H and Schneider B. (2008). The Meaning of Employee Engagement. Industrial and Organizational Psychology, 1 (2008), 3-30.
[14] Meijaard, A. Y., Brend, O. \& Mosselean, L. (2002) Commitment in the workplace: toward a general model. Human Resource Management Review, 11(2), 299-326.

[15] Meyer, J. P. and Allen, N. J. (1997), Commitment in the workplace: Theory, research, and application. Thous and Oaks, CA: Sage.

[16] Moore, N. (2011). Measuring job satisfaction from the perspective of interpersonal relationship and faculty workload among academic staff at public universities in Kelantan, Malaysia. International Journal of Business and Social Science 4 (15)

[17] Perrin T. (2003). Working Today: Understanding What Drives Employee Engagement The 2003 Towers Perrin Talent Report U.S Report. [Online] Available:

http://www.towersperrin.com/tp/getwebcachedoc? Webc = HRS /USA/2003/200309/Talent_2003.pdf (May 21, 2018)

[18] Phua, A.E. (2012). Impact of employee commitment on productivity in banking sectors. Industrial and organizational psychology, 7(2), 135-141.

[19] Robert, H. (1996), Relationship between task performance, contextual performance and turnover rate, job satisfaction affective commitment. Human Resource Management Review, 3 (1), 32.

[20] Robbins, S.P. \& Coulter, A.W. (2003). Training strategy: An effective tool for employee's commitment to work. Journal of Industrial Relation, 1(1), 51-57.

[21] Robinson, D, Dilys, F. \& Heyday, M. M. (2003). Organisational culture and climate, in work and culture handbook of psychology. Industrial and Organisational Psychology, 12(5), 565-593.

[22] Robinson D., Perryman S., and Hayday S. (2004). The Drivers of Employee Engagement Report 408, Institute for Employment Studies, UK

[23] Schmidt, B., Henges, M. \& Bryson, A. (2003). A critical review of health-related productivity measures. Journal of Business and Psychology, 5(6), 535-536.

[24] Seijts, G., Gerand, F., \& Crim, D. (2006). The combined effects of goal type and cognitive ability on performance. International Journal of Human Resource Management, 3(2), 23-56.

[25] Spreitzer, G.M. (1995). Psychological empowerment in the workplace: Dimensions, measurement, and validation. Academy of Management Journal, 38(5): 1442-1466.

[26] Steven M. Elias, Rakesh Mittal, (2011) "The importance of supervisor support for a change initiative: An analysis of job satisfaction and involvement", International Journal of Organizational Analysis, Vol. 19 Iss: 4, pp.305316.

[27] Trek, J. (1994). Statistics for Beginners, USA: South Western Cengage Learning.

[28] White, R.E. (2001). Generic business strategies, organisational context, and Performance: empirical investigation. Strategic Management Journal, 7(2), 17-31. 